\title{
Isomeric cross sections of neutron induced reactions on Ge and Ir isotopes
}

\author{
R. Vlastou ${ }^{1, a}$, C.T. Papadopoulos ${ }^{1}$, M. Kokkoris ${ }^{1}$, G. Perdikakis ${ }^{1,2}$, S. Galanopoulos ${ }^{1}$, N. Patronis ${ }^{1}$, M. Serris ${ }^{1}$, \\ S. Harissopulos ${ }^{2}$, and P. Demetriou ${ }^{2}$ \\ 1 National Technical University of Athens, Department of Physics, 15780 Athens, Greece \\ 2 NCSR "Demokritos", Institute of Nuclear Physics, 15310 Athens, Greece
}

\begin{abstract}
The ${ }^{72} \mathrm{Ge}(\mathrm{n}, \alpha){ }^{69 \mathrm{~m}} \mathrm{Zn},{ }^{74} \mathrm{Ge}(\mathrm{n}, \alpha){ }^{71 \mathrm{~m}} \mathrm{Zn},{ }^{76} \mathrm{Ge}(\mathrm{n}, 2 \mathrm{n}){ }^{75 \mathrm{~g}+\mathrm{m}} \mathrm{Ge}$ and ${ }^{191} \operatorname{Ir}(\mathrm{n}, 2 \mathrm{n}){ }^{190} \operatorname{Ir} \mathrm{g}+\mathrm{m} 1$ and ${ }^{191} \operatorname{Ir}(\mathrm{n}, 2 \mathrm{n}){ }^{190} \mathrm{I}_{\mathrm{rm} 2}$ reaction cross sections were measured from 9.6 to $11.4 \mathrm{MeV}$ relative to the ${ }^{27} \mathrm{Al}(\mathrm{n}, \alpha)^{24} \mathrm{Na}$ reference reaction via the activation method. The quasi-monoenergetic neutron beams were produced via the ${ }^{2} \mathrm{H}(\mathrm{d}, \mathrm{n}){ }^{3} \mathrm{He}$ reaction at the $5 \mathrm{MV}$ VdG Tandem T11/25 accelerator of NCSR "Demokritos". Statistical model calculations using the codes STAPRE-F and EMPIRE (version 2.19) and taking into account pre-equilibrium emission were performed on the data measured in this work as well as on data reported in literature.
\end{abstract}

\section{Introduction}

Studies of neutron induced reactions are of considerable significance, both for their importance to fundamental research in Nuclear Physics and Astrophysics and for practical applications in nuclear technology, medicine and industry [1]. In the energy region up to $20 \mathrm{MeV}$, many reaction channels, such as $(\mathrm{n}, 2 \mathrm{n}),(\mathrm{n}, \mathrm{p})$ and $(\mathrm{n}, \alpha)$, which may proceed via different reaction mechanisms, are open and therefore can be simultaneously studied both experimentally and theoretically. Of special interest is the study of reactions in which the residual nucleus has one or more metastable states, since the population of the isomers is governed by the nuclear spin of both the discrete levels involved and the continuum [2,3]. Experimental and theoretical studies of isomeric to ground state cross sections as a function of energy, could lead to valuable information concerning the spin distribution of level density which is related to the effective moment of inertia on the produced nucleus.

In this work, the ${ }^{72} \mathrm{Ge}(\mathrm{n}, \alpha){ }^{69 \mathrm{~m}} \mathrm{Zn},{ }^{74} \mathrm{Ge}(\mathrm{n}, \alpha)^{71 \mathrm{~m}} \mathrm{Zn}$, ${ }^{76} \mathrm{Ge}(\mathrm{n}, 2 \mathrm{n}){ }^{75 \mathrm{~g}+\mathrm{m}} \mathrm{Ge}$ and ${ }^{191} \operatorname{Ir}(\mathrm{n}, 2 \mathrm{n}){ }^{190} \mathrm{Ir}_{\mathrm{g}+\mathrm{m} 1}$ and ${ }^{191} \operatorname{Ir}(\mathrm{n}, 2 \mathrm{n})$ ${ }^{190} \mathrm{Ir}_{\mathrm{m} 2}$ reaction cross sections were measured from 9.6 to $11.4 \mathrm{MeV}$ relative to the ${ }^{27} \mathrm{Al}(\mathrm{n}, \alpha)^{24} \mathrm{Na}$ reference reaction via the activation method.

\section{Experimental}

The measurements were carried out at the $5 \mathrm{MV}$ Tandem T11/25 accelerator laboratory of NCSR "Demokritos". Quasi-monoenergetic neutron beams were produced via the ${ }^{2} \mathrm{H}(\mathrm{d}, \mathrm{n})^{3} \mathrm{He}$ reaction at a flux of the order of $10^{6} \mathrm{n} /\left(\mathrm{cm}^{2} \mathrm{sec}\right)$. The absolute flux of the beam was obtained with respect to the ${ }^{27} \mathrm{Al}(\mathrm{n}, \alpha)^{24} \mathrm{Na}$ reference reaction, while its variation was monitored by a BF3 detector placed at a distance of $3 \mathrm{~m}$ from the neutron source. Another two reference reactions of different thresholds $\left({ }^{93} \mathrm{Nb}(\mathrm{n}, 2 \mathrm{n}){ }^{92 \mathrm{~m}} \mathrm{Nb}\right.$ and $\left.{ }^{197} \mathrm{Au}(\mathrm{n}, 2 \mathrm{n}){ }^{196} \mathrm{Au}\right)$ were

\footnotetext{
${ }^{a}$ Presenting author, e-mail: vlastou@central.ntua.gr
}

also used in order to verify the results from the ${ }^{27} \mathrm{Al}(\mathrm{n}, \alpha){ }^{24} \mathrm{Na}$ reaction, whose cross section is well defined in literature [4].

For the reactions on Ge isotopes, samples of high purity natural $\mathrm{Ge}$ in the form of pellets of $1.3 \mathrm{~cm}$ diameter and $\sim 0.7 \mathrm{gr}$ weight, doped with $12 \%$ high purity $\mathrm{C}$ were used, while for the Ir reactions, high purity natural Ir foils of the same diameter were used for the irradiations. The reference targets were thin metallic foils of high purity $\mathrm{Al}, \mathrm{Nb}$ and $\mathrm{Au}$, all identically shaped. The samples were placed between the reference foils and exposed to the neutron beam for about 2 days of continuous irradiation. The induced activity of product radionuclides in both target and reference foils was measured with a HPGe detector of $56 \%$ efficiency, properly shielded with lead blocks in order to reduce the contribution of the natural radioactivity. The efficiency of the detector at the position of the activity measurements was determined via a calibrated ${ }^{152}$ Eu source. The cross section was deduced by measuring the characteristic gamma rays from the decay of the residual nuclei, corrected for self absorption of the sample, coincidence summing effects of cascading gamma rays and counting geometry. Furthermore, the decay of produced nuclides over the whole time range and the fluctuation of the neutron beam flux over the irradiation time were taken into account. The Monte Carlo code MCNP [5] was utilized to perform simulations and to test the reliability of the various corrections. More details about the experimental measurements, the neutron fluxes and data analysis can be found in ref. [6,7].

\section{$2.1{ }^{191} \operatorname{Ir}(n, 2 n)$ reaction measurements}

The ${ }^{191} \operatorname{Ir}(n, 2 n){ }^{190} \operatorname{Ir}$ reaction leads to the formation of ${ }^{190} \mathrm{Ir}$ in its $11^{-}$second metastable $\mathrm{m} 2$ state $\left(\mathrm{T}_{1 / 2}=3.087 \mathrm{~h}\right)$ as well as its ground $4^{-}$state $\left(\mathrm{T}_{1 / 2}=11.78 \mathrm{~d}\right)$ and its first metastable $\mathrm{m} 1$ $1^{-}$state $\left(\mathrm{T}_{1 / 2}=1.12 \mathrm{~h}\right)$. The $\mathrm{m} 2$ state decays $(91.4 \%)$ to ${ }^{190} \mathrm{Os}$, whose characteristic gamma rays 502.5 and $616.5 \mathrm{keV}$ can be used for the determination of the activation cross section $\sigma_{\mathrm{m} 2}$. The intensity measurement of these lines started 2-4 hours after the end of the irradiation and lasted for $10 \mathrm{~h}$. Due to the short half life of $\mathrm{m} 1$, the sum of the isomeric $\mathrm{m} 1$ and ground state cross sections $\sigma_{\mathrm{m} 1+\mathrm{g}}$ was determined via the 518.5, 557.9 

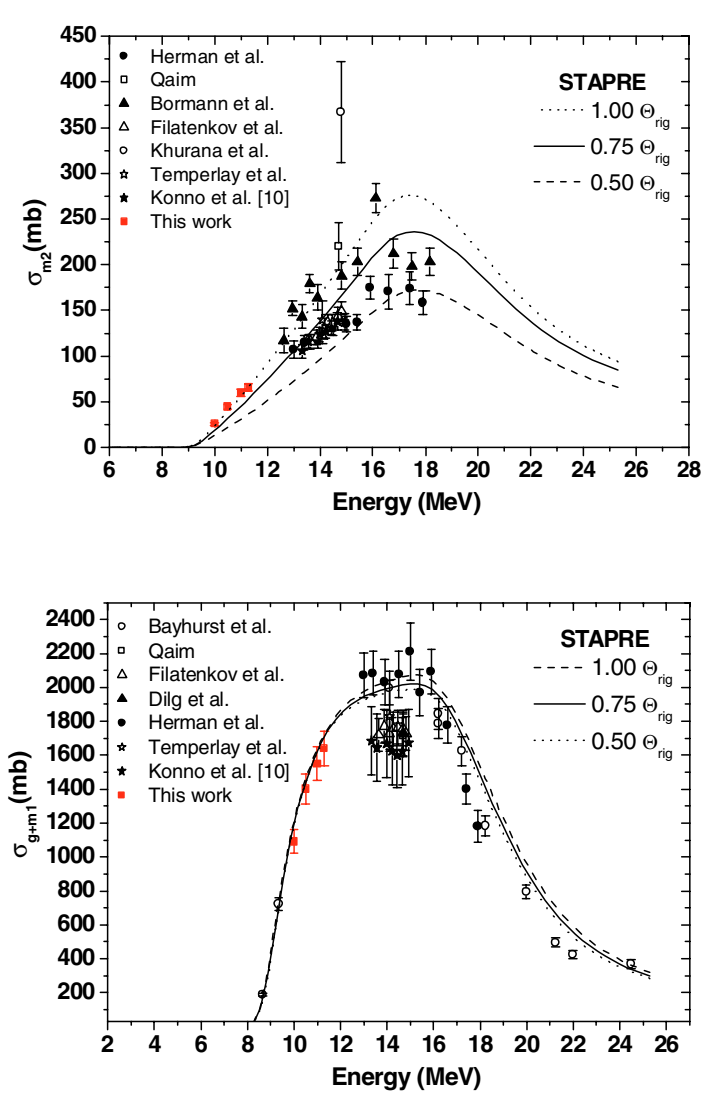

Fig. 1. The measured and calculated cross section $\sigma_{\mathrm{g}+\mathrm{m} 1}$ for the population of the ground and first isomeric state of ${ }^{190} \mathrm{Ir}$.

and $569.3 \mathrm{keV}$ transitions of ${ }^{190} \mathrm{Os}$. The intensity measurement of these lines started $16 \mathrm{~h}$ after the end of the irradiation to ensure full decay of $\mathrm{ml}^{-}$isomeric state to the ground state of ${ }^{190} \mathrm{Ir}$. The $\sigma_{\mathrm{m} 2}$ and $\sigma_{\mathrm{m} 1+\mathrm{g}}$ cross sections were determined for neutron energies 10.0, 10.5, 11.0 and $11.3 \mathrm{MeV}$. The data are presented in figure 1 along with data from literature [8-16] at higher energies and theoretical predictions.

\section{$2.2{ }^{72,744} \mathrm{Ge}(\mathrm{n}, \alpha)^{69,71 \mathrm{~m}} \mathrm{Zn}$ and ${ }^{76} \mathrm{Ge}(\mathrm{n}, 2 \mathrm{n})^{75 \mathrm{~g}+\mathrm{m}} \mathrm{Ge}$ reaction measurements}

Among all isotopes comprising natural $\mathrm{Ge}$, only the ${ }^{72,74} \mathrm{Ge}(\mathrm{n}, \alpha){ }^{69,71} \mathrm{Zn}$ and ${ }^{76} \mathrm{Ge}(\mathrm{n}, 2 \mathrm{n}){ }^{75} \mathrm{Ge}$ reactions lead to metastable states which can be measured via the activation technique. The ${ }^{72} \mathrm{Ge}(\mathrm{n}, \alpha)^{69} \mathrm{Zn}$ reaction leads to the formation of the unstable nucleus ${ }^{69} \mathrm{Zn}$ both in its $1 / 2^{-}$ground state $\left(\mathrm{T}_{1 / 2}=56.4 \mathrm{~h}\right)$ and its metastable $9 / 2^{+}\left(\mathrm{T}_{1 / 2}=13.76 \mathrm{~h}\right)$ state. The ground state of ${ }^{69} \mathrm{Zn}$ decays directly to the ground state of ${ }^{69} \mathrm{Ga}$, while the metastable state decays to the ground state $(99.967 \%)$ of ${ }^{69} \mathrm{Zn}$ emitting the characteristic $438.6 \mathrm{keV}$ gamma ray which can be used for the determination of the $\sigma_{m}$ cross section. The contamination in the production of ${ }^{69} \mathrm{Zn}$ by the ${ }^{73} \mathrm{Ge}(\mathrm{n}, \mathrm{n} \alpha)^{69} \mathrm{Zn}$ reaction, is negligible, due to the its low cross section in this energy region as well as the lower abundance of ${ }^{73} \mathrm{Ge}$ relative to ${ }^{72} \mathrm{Ge}$.

The ${ }^{74} \mathrm{Ge}(\mathrm{n}, \alpha)^{71} \mathrm{Zn}$ reaction leads to the formation of the unstable nucleus ${ }^{71} \mathrm{Zn}$ both in its $1 / 2^{-}$ground state $\left(\mathrm{T}_{1 / 2}=\right.$

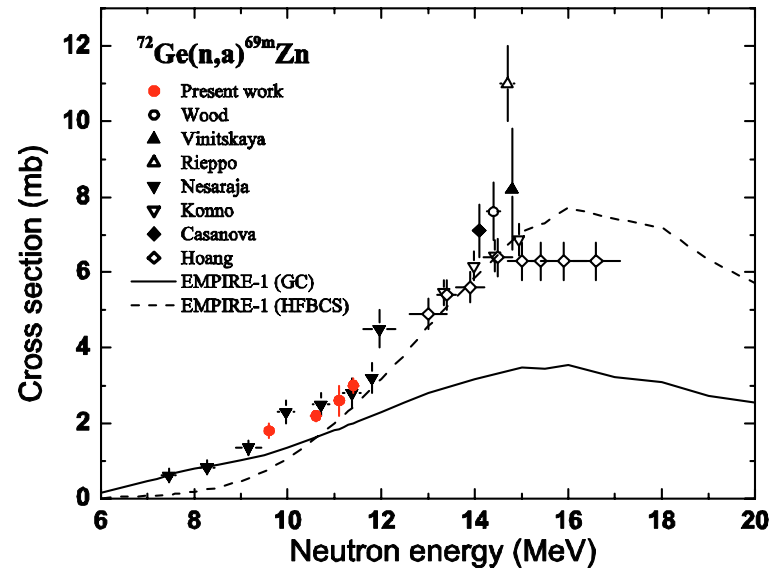

Fig. 2. Cross section measurements of ${ }^{72} \mathrm{Ge}(\mathrm{n}, \alpha)^{69 \mathrm{~m}} \mathrm{Zn}$ reaction along with data from literature and comparison with theoretical predictions with the code EMPIRE-II.

$2.45 \mathrm{~m})$ and its metastable $9 / 2^{+}\left(\mathrm{T}_{1 / 2}=3.96 \mathrm{~h}\right)$ state. Due to short lifetime of the ground state of ${ }^{71} \mathrm{Zn}$, only the activity of the metastable state could be measured via the activation technique. Thus the $\sigma_{\mathrm{m}}$ could be determined by analyzing the $386.3 \mathrm{keV}$ transition of ${ }^{71} \mathrm{Ga}$ which is fed by the deexcitation of the metastable state of ${ }^{71} \mathrm{Zn}$.

The high threshold ${ }^{76} \mathrm{Ge}(\mathrm{n}, 2 \mathrm{n})^{75} \mathrm{Ge}$ reaction leads to the formation of the unstable nucleus ${ }^{75} \mathrm{Ge}$ both in its $1 / 2^{-}$ground state $\left(\mathrm{T}_{1 / 2}=82.78 \mathrm{~m}\right)$ and its metastable $7 / 2^{+}\left(\mathrm{T}_{1 / 2}=\right.$ $47.7 \mathrm{~s})$ state. The deexcitation of the metastable to the ground state in fraction $99.97 \%$ along with its short lifetime lead to the measurement of the total cross section $\sigma_{\mathrm{m}+\mathrm{g}}$ of the $(\mathrm{n}, 2 \mathrm{n})$ reaction via the $264.6 \mathrm{keV}$ characteristic transition of ${ }^{75} \mathrm{As}$. The formation of the residual nucleus ${ }^{75} \mathrm{Ge}$ can be also achieved by the interfering ${ }^{74} \mathrm{Ge}(\mathrm{n}, \gamma){ }^{75} \mathrm{Ge}$ reaction which is important at thermal neutron energies. In order to estimate this neutron background contribution to the activation of ${ }^{75} \mathrm{Ge}$ and make the appropriate corrections, an irradiation has been performed just below the threshold of the $(n, 2 n)$ reaction, where the product radioactivity is expected to derive only from the disturbing $(\mathrm{n}, \gamma)$ reaction.

The neutron irradiations on natural Ge have been performed at energies 9.6, 10.6, 11.1 and $11.4 \mathrm{MeV}$. The data are presented in figures 2, 3 and 4 along with data from literature $[2,17-23]$ and theoretical predictions.

\section{Calculations}

The production of high spin isomeric states in neutron induced reactions has attracted special interest since it is strongly related to the effect of nuclear spin $[2,3]$. The production cross section of a metastable state is highly dependent not only on the branching ratios, spin and parities of the discrete levels of the residual nucleus [24] but also on their shell model configurations [25]. The measurements of isomeric cross sections are also important for the investigation of the spin distribution of level densities involved in model predictions [26,27] as well as on the spin cutoff parameter and consequently on the moment of inertia of the produced nucleus [28,29]. 


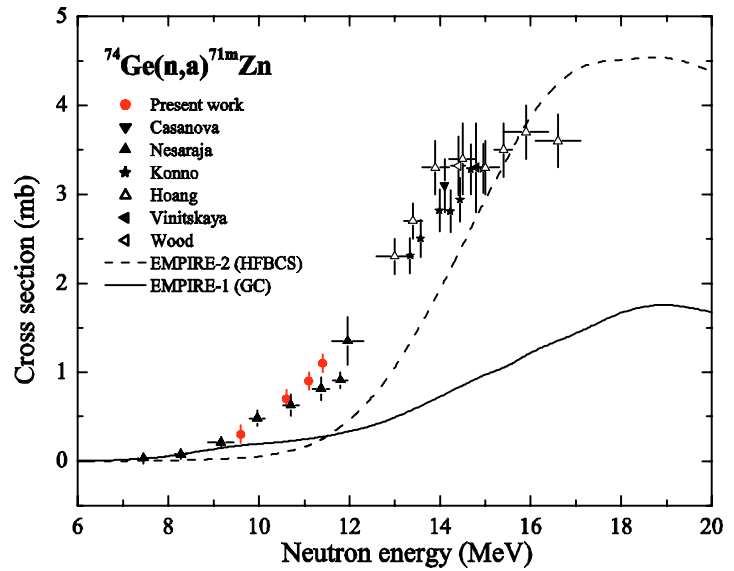

Fig. 3. Cross section measurements of ${ }^{74} \mathrm{Ge}(\mathrm{n}, \alpha)^{71 \mathrm{~m}} \mathrm{Zn}$ reaction along with data from literature and comparison with theoretical predictions with the code EMPIRE-II.

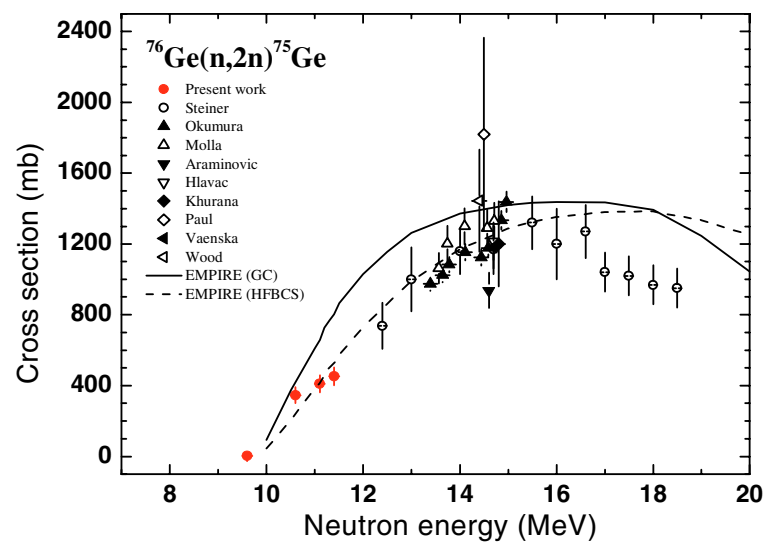

Fig. 4. Cross section measurements of ${ }^{76} \mathrm{Ge}(\mathrm{n}, 2 \mathrm{n})^{75 \mathrm{~g}+\mathrm{m}} \mathrm{Ge}$ reaction along with data from literature and comparison with theoretical predictions with the code EMPIRE-II.

\section{$3.1{ }^{191} \operatorname{Ir}(\mathrm{n}, 2 \mathrm{n})$ reaction}

Cross section calculations have been performed using the code STAPRE-F [30], taking into account preequilibrium effects via the exciton model [31] along with the new up-to-date level scheme of ${ }^{190} \mathrm{Ir}$, which was found to be crucial for the determination of the isomeric cross section [7]. In the continuum region, the level density was calculated using the Generalized Superfluid Model (GSM), in the form of the phenomenological model provided by Ignatyuk et al. [32], which takes into account shell, pairing and collective effects. To the authors best knowledge, the GSM is tested for the first time in the mass region $\sim 190$ and for isomeric cross section production. Despite the fact that Ir isotopes are transitional nuclei and exhibit very complex structures, the level density calculations using GSM, reproduce fairly well the experimental data (dotted line in figure 1).

In order to better reproduce the data for the high spin isomer, several attempts have been tried to vary the parameter $\tilde{\alpha}$ affecting the energy dependence of the nuclear level density, as well as the total radiation width affecting the gamma ray strength and the shape and symmetry of the Ir isotopes that belong in the transitional region from well deformed to spherical nuclei. The theoretical calculations, however, did not exhibit any significant sensitivity to all these parameters. On the contrary, it seems that the rigid body moment of inertia $\Theta$ rig, is the most sensitive parameter which could affect the results. A reduction of $\Theta$ rig by $\sim 25 \%$ is required to in order to obtain a better description of the isomeric cross sections both in the high and low energy region (solid line in figure 1). The sensitivity to the moment of inertia is expected to be significant, since only a small part of the continuum deexcites by feeding the high spin state of the discrete and this part is strongly determined by the spin distribution of the level density and consequently by the moment of inertia $\Theta$ rig.

\section{$3.2{ }^{72,744} \mathrm{Ge}(\mathrm{n}, \alpha)^{69,71 \mathrm{~m}} \mathrm{Zn}$ and ${ }^{76} \mathrm{Ge}(\mathrm{n}, 2 \mathrm{n})^{75 \mathrm{~g}+\mathrm{m}} \mathrm{Ge}$ reactions}

Cross section calculations have been performed for the data of the present work along with data from literature, using the statistical model code EMPIRE-II [33] and taking into consideration appropriate pre-equilibrium effects. The influence of the pre-equilibrium reaction mechanism on the predictions was found to increase progressively with increasing neutron energy and varies from 7 to $10 \%$ at $14 \mathrm{MeV}$, depending on the Ge isotope under study. The effect of the different optical model potentials (OMP) has been investigated and the OMP of Koning-Delaroche [34] for neutrons and protons and that of Avrigeanu [35] for $\alpha$ particles, were found to better reproduce the data and were employed in the calculations.

The effect of different nuclear level density models (NLD) on the statistical model calculations has been tested in the case of $(\mathrm{n}, \alpha)$ and $(\mathrm{n}, 2 \mathrm{n})$ reactions leading to metastable states. The Gilbert-Cameron approach [36] (solid lines in figs. 2, 3 and 4) fails to reproduce the data, while the microscopic Hartree-Fock-BCS (HFBCS) [37,38] level densities exhibit a fair agreement with the measurements (dashed lines in figs. 2, 3 and 4). On the other hand, the HFBCS predictions for the $(n, p)$ reactions on $\mathrm{Ge}$ isotopes tend to overestimate the data. Further investigation is needed in order to draw firm conclusions for the simultaneous representation of all $(n, p)$, $(\mathrm{n}, \alpha)$ and $(\mathrm{n}, 2 \mathrm{n})$ reactions on $\mathrm{Ge}$ isotopes.

The authors would like to thank the operational staff of Tandem accelerator in "Demokritos" for their assistance during the irradiations. The project is co-funded by the European Social Fund (75\%) and National Resources (25\%)-(EPEAEK II) - PYTHAGORAS II.

\section{References}

1. A. Fessler et al., Nucl. Sci. Eng. 134, 171 (2000).

2. C.D. Nasaraja et al., Phys. Rev. C 68, 024603 (2003).

3. M. Al-Abyad et al., Phys. Rev. C 73, 064608 (2006).

4. The International Reactor Dosimetry File 2002, Nuclear Data Section, IAEA, Vienna.

5. MCNP-A general Monte Carlon-particle Transport code, version 4C, Report LA-13709-M, Los Alamos National Laboratory, edited by J.F. Briesmeister, April 2000.

6. G. Perdikakis et al., Phys. Rev. C 73, 067601 (2006).

7. N. Patronis et al., Phys. Rev. C 75, 034607 (2007). 
8. C.S. Kuhurana et al., Nucl. Phys. A 28, 560 (1961).

9. W. Dilg et al., Nucl. Phys. A 118, 9 (1968).

10. J.K. Temperley, D.E. Barnes, Ballistic Research Labs Reports No. 1491 (1970).

11. M. Borman et al., Nucl. Phys. A 157, 481 (1970).

12. M. Qaim, Nucl. Phys. A 185, 614 (1972).

13. M. Herman et al., Nucl. Phys. A 430, 69 (1984).

14. D.M. Zellermayer, B. Rosner, Phys. Rev. C 6, 315 (1972).

15. C. Conno et al., JAERI Tokai Report Series, No. 1329 (1993).

16. A.A. Filatenkov, S.V. Chuvaev, Khlopin Radiev. Inst. Leningrad Reports No. 259 (2003).

17. H.M. Hoang et al., Z. Phys. A 342, 283 (1992).

18. C. Conno et al., JAERI Reports-1329, 1993.

19. R. Rieppo et al., J. Inorg. Nucl. Chemistry 38, 1927 (1976).

20. J.L. Casanova et al., Annales de Fisica y Quimica 72, 186 (1976).

21. G.P. Vinitskaya et al., Yadernaya Fizika 5, 1175 (1967).

22. R.E. Wood et al., Phys. Rev. 154, 1108 (1967).

23. N.I. Molla et al., in Proceedings of the International Conference on Nucl.Data for Sci. and Technol., Trieste (1977), p. 517.
24. S. Sudar, S.M. Qaim, Phys. Rev. C 53, 2885 (1996).

25. K. Gul, Phys. Rev. C70, 034602 (2004).

26. I.-G. Birn et al., Phys. Rev. C 52, 2546 (1995).

27. M.B. Chadwick, P.G. Young, Nucl. Sci. Eng. 108, 117 (1991).

28. B.K. Agrawal et al., Phys. Rev. C 59, 3109 (1999).

29. S.I. Al-Quraishi et al., Phys. Rev. C67, 015803 (2003).

30. M. Uhl, B. Strohmaier, IRK-76/01, IRK, Vienna (1976).

31. J.J. Griffin, Phys. Rev. Lett. 17, 478 (1966).

32. A.V. Ignatyuk et al., Sov. J. Nucl. Phys. 29, 450 (1979).

33. M. Herman et al., EMPIRE-2.19, A modular system for nuclear reaction calculations.

34. A.J. Koning, J.P. Delaroche, Nucl. Phys. A 713, 231 (2003).

35. V. Avrigeanu et al., Phys. Rev. C 49, 2136 (1994).

36. A. Gilbert, A.G.W. Cameron, Can. J. Phys. 43, 1446 (1965).

37. J. Bardeen, L. Cooper, J.R. Schrieffer, Phys. Rev. 108, 1175 (1957).

38. P. Demetriou, S. Goriely, Nucl. Phys. A 695, 95 (2001). 